\title{
Anti TPO and Miscarriages: A Literature Review and a Case-Control Study
}

\author{
Georges Abi Tayeh ${ }^{1,2 *}$, Samer Maalouf1, Ramzi Finan ${ }^{1,2}$ and Elie Attieh ${ }^{1,2}$ \\ ${ }^{1}$ Department of Obstetrics and Gynecology, Hotel Dieu de France University Hospital, Lebanon \\ ${ }^{2}$ Department of Obstetrics and Gynecology, Saint Joseph University, Lebanon
}

*Corresponding author: Georges Abi Tayeh, Department of Obstetrics and Gynecology, Hotel Dieu st, Ashrafieh, Beirut, Lebanon

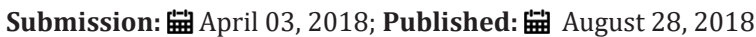

\begin{abstract}
Introduction: Thyroid peroxidase antibodies (TPO-Ab) in women are associated with fertility and early pregnancy loss. Many studies confirmed this relationship and explained their way of acting.

Materiel and methods: This is a descriptive retrospective study done by a single institution in Beirut, Lebanon, between 2015 and 2016. All women diagnosed having infertility problems were randomly chosen to be tested for thyroid peroxidase antibodies. 196 women approved to participate. Obstetrical data were collected from these women and their characteristics were analyzed and compared.

Result: 69 patients had positive thyroid peroxidase antibodies aTPO (39.4\%) and 106 women had negative results. These 69 patients have a higher number of miscarriages without any significant difference. Among 86 patients who had at least a history of one miscarriage, 34 women (39.5\%) had positive aTPO versus 35 (39.3\%) among 89 patients with no history of miscarriages (no significant difference, $\mathrm{p}=0.55$ ).
\end{abstract}

Conclusion: Thyroid peroxidase antibodies (TPO-Ab) can be an independent risk factor for infertility. Larger studies should be done to confirm this relationship.

\section{Introduction}

Thyroid dysfunction is relatively common in pregnancy and is associated with menstrual irregularities, fertility problems and increased miscarriage rates [1]. The odds of miscarriage and preterm delivery in the presence of thyroid auto-antibodies are significantly increased at 3,9 (95\% CI: 2,48-6,12) and 2,07 (95\% CI: 1,17-3,68), respectively [2]. The presence of antibodies to thyroid peroxidase (aTPO) is highly prevalent in women of reproductive age: 8-14\% [3]. In women with recurrent miscarriages and infertility, aTPO have a prevalence of 14-33\% [4]. Although TPO antibody positivity is associated with thyroid autoimmune disorders, majority of these women are euthyroid [5]. Approximately 15-20\% of TPO antibody positive women, who are euthyroid outside pregnancy, will have elevated TSH by the 3rd trimester of pregnancy. Thus, in untreated TPO antibody positive women thyroid function monitoring is warranted in each trimester of pregnancy [6]. The available evidence on thyroid peroxidase antibodies (aTPO) and their effect on reproduction are: aTPO are present in follicular fluid but do

not influence the number of retrieved oocytes during controlled ovarian stimulation. aTPO are associated with lower fertilization rates and disturbed embryogenesis but do not influence endome trial volume neither implantation. They diffuse through the pla cental barrier but there is no evidence for a direct effect of aTPO on early placentation [7]. This paper is a descriptive retrospective study searching to establish a relationship between thyroid peroxidase antibodies and miscarriages and it aims to provide a summary of thyroid peroxidase antibodies impact in obstetrics.

\section{Material and Methods}

This is a descriptive retrospective study done by a single institution in Beirut, Lebanon between 2015 and 2016. All women consulting for infertility without any obvious results (normal ultrasound and hysterosalpingography, normal karyotype, normal semen analysis and negative thrombophilia) were randomly chosen and asked for approval to be tested for thyroid peroxidase antibodies.

\section{Inclusion criteria}

Women having a fertility problem defined by the inability to achieve a normal complete pregnancy after at least a period of 12 months of trying. Both primary and secondary infertility cases were included, 


\section{Exclusion criteria}

All women with known cause of infertility: abnormal karyotype, abnormal semen analysis and structural abnormality on ultrasound or hysterosalpingography, abnormal tests (thyroid disease, diabetes and antiphospholipid antibodies).

\section{Collected obstetrical and medical data were}

Age, Gravida, Parity, history of miscarriages, medical problems especially of auto-immune diseases, smoking habits, drinking habits and history of medically assisted procreation. Data were analyzed using SPSS software version 20. Statistical analysis for ordinal variables was done by Fisher Test and continuous variables were compared using T-Test.

Result

196 women approved to participate in this study. Two of them were excluded for having auto-immune thyroid disease (clinically apparent and treated thyroid disease). Nineteen women were excluded for having other suspected causes of infertility. Thus, final data analysis concerned 175 patients. 69 patients had positive thyroid peroxidase antibodies a TPO (39.4\%) and 106 women had negative results. Only one woman was a smoker. The mean age of our population was 33 years old. Mean Gravida was 1,7 and mean parity was 1 . We divided our population in two groups. Group A had at least 1 miscarriage and group B had no history of miscarriages. 86 women $(49 \%)$ had at least one miscarriage and group B consisted of 89 women (51\%). Among group A, the mean value of aTPO in their blood tests was $8.4 \mathrm{Ul} / \mathrm{ml}$. Group B had a mean value of $30.7 \mathrm{Ul} / \mathrm{ml}$ of aTPO (no significant difference, $\mathrm{p}=0.147$ ). Among group A, 34 women had positive aTPO (39.5\%) and among group B 35 patients had positive TPO antibodies (39.3\%). This small increase in difference was not significant $(p=0.55)$. (Table 1) When re-dividing our population by the positivity of TPO antibodies, we found that patients with positive results were younger, had higher values of gravida and parity and a higher number of miscarriages without any significant difference (Table 2).

Table 1.

\begin{tabular}{|c|c|c|c|c|}
\hline \multirow{2}{*}{ Anti TPO } & & Group A & Group B & Total \\
\cline { 2 - 5 } & & & & \\
\cline { 2 - 5 } & Negative & $52(49.1 \%)$ & $54(50.9 \%)$ & 106 \\
\cline { 2 - 5 } & Positive & $34(49.3 \%)$ & $35(50.7 \%)$ & 69 \\
\hline \multicolumn{2}{|c|}{ Total } & & & 175 \\
\hline
\end{tabular}

Table 2.

\begin{tabular}{|c|c|c|c|c|c|}
\hline \multicolumn{2}{|c|}{ Anti TPO } & Age & Gravida & Parity & Number of Miscarriages \\
\hline Negative & Mean & 33.2 & 1.6 & 0.9 & 0.7 \\
\hline Positive & Mean & 33 & 1.8 & 1 & 0.8 \\
\hline Total & Mean & 33.1 & 1.7 & 0.9 & 0.8 \\
\hline & P & 0.75 & 0.353 & 0.669 & 0.638 \\
\hline
\end{tabular}

Discussion

This is a descriptive retrospective study where 175 women tested for thyroid peroxidase antibodies had their obstetrical data compared. Its results demonstrated an increased risk of miscarriage in women with positive a TPO but without any significant difference. Recent literature links thyroid autoimmunity as a cause of infertility and adverse pregnancy outcomes that includes miscarriage or preterm deliveries. The first diagnosis to think about in front of hypothyroidism is Hashimoto disease. The presence of aTPO predisposes to hypothyroidism but majority of women with aTPO are euthyroid [8]. Negro et al. [9] compared 245 euthyroid women with aTPO to 3348 women without aTPO in the first trimester. Positivity to aTPO was associated with an increased rate of preterm deliveries. TSH level was similar between the two groups (0.82 vs. $1.25 \mathrm{mI}-$ $\mathrm{U} / \mathrm{L}$ ). These findings are in accordance with previous prospective works reporting 2-3-fold increase in the rate of preterm deliveries in thyroid antibody positive antibody positive women compared to control $[5,10]$. In our study, women with positive aTPO had higher prevalence of miscarriages but no significant difference. All of them were euthyroid and had no medical co morbidities.
Van den Boogaard et al. [3] indicated that TPO antibody are associated with subfertility (OR 1,5, 95\% CI: 1,1-2,0). A recent meta-analysis concluded that this relationship is independent of age [2]. In our study women with positive aTPO were younger but also no significant difference was found. How these antibodies could affect pregnancy rates was the subject of many studies. Thyroid auto antibodies could act by significant increase of endometrial T cells with reduced secretion of IL- 4 and IL-10 along with hyper secretion of Interferon-g and activation of polyclonal B cells [11]. Activated $\mathrm{T}$ cells in the uteri of women with anti-thyroid antibodies secrete cytokines that hamper successful pregnancy $[12,13]$. Though many studies indicated a significant increase of miscarriages in women with positive a TPO, this study concluded that there was no significant difference. This study included cases of primary and secondary infertility. Larger studies should be done to confirm the presence or absence of significant relationship between these 2 variables.

\section{Conclusion}

Thyroid peroxidase antibodies (TPO-Ab) can be an independent risk factor for infertility. Its mechanism of action is even through 
subclinical hypothyroidism or by affecting local immunity. Larger studies should be done to confirm this relationship and if true to find the reliable remedy to prevent its consequences.

\section{Declarations}

\section{Ethics approval and consent to participate}

The study was approved by the ethical committee of the participating center before it was initiated. All participants were interviewed after having signed their written informed consent. Data collection and analysis were performed. Patients were entitled to their autonomous decision and their anonymity was protected.

\section{Consent for publication}

Consent for publication was obtained from all participants.

\section{Availability of data and materials}

The dataset supporting the conclusions of this article is available upon request from the corresponding author.

The authors hereby transfer, assign or otherwise convey all copyright ownership to the Order of Physicians in Lebanon in event that such work is published by the Order of Physicians in Lebanon.

\section{References}

1. Krassas GE, Poppe K, Glinoer D (2010) Thyroid function and human reproductive health. Endocr Rev 31(5): 702-755.

2. Thangaratinam S, Tan A, Knox E, Kilby MD, Franklyn J, et al. (2011) Association between thyroid autoantibodies and miscarriage and preterm birth: meta-analysis of evidence. BMJ 342: 2616.

3. Van den Boogaard E, Vissenberg R, Land J, Van Wely M, Van der Post JA, et al. (2011) Significance of (sub) clinical thyroid dysfunction and thyroid autoimmunity before conception and in early pregnancy: a systematic review. Hum Reprod Update 17(5): 605-619.

4. Chevrier J, Harley KG, Kogut K, Holland N, Johnson C, et al. (2011) Maternal thyroid function during the second half of pregnancy and child neurodevelopment at 6,12, 24, and 60 months of age. Journal of Thyroid Research 426427: 1-13.
5. Glinoer D, Riahi M, Grun JP, Kinthaert J (1994) Risk of subclinical hypothyroidism in pregnant women with asymptomatic autoimmune thyroid disorders. J Clin Endocrinol Metab 79(1): 197-204.

6. Negro R, Formoso G, Mangieri T, Pezzarossa A, Dazzi D, et al. (2006) Levothyroxine treatment in euthyroid pregnant women with autoimmune thyroid disease: effects on obstetrical complications. J Clin Endocrinol Metab 91(7): 2587-2591.

7. Vissenberg R, Manders VD, Mastenbroek S, Fliers E, Afink GB, et al. (2015) Pathophysiological aspects of thyroid hormone disorders/ thyroid peroxidase autoantibodies and reproduction. Hum Reprod Update 21(3): 378-387.

8. Bellver J, Soares SR, Alvarez C, Muñoz E, Ramírez A, et al. (2008) The role of thrombophilia and thyroid autoimmunity in unexplained infertility, implantation failure and recurrent spontaneous abortion. Hum Reprod 23(2): 278-284.

9. Negro R, Schwartz A, Gismondi R, Tinelli A, Mangieri T, et al. (2011) Thyroid antibody positivity in the first trimester of pregnancy is associated with negative pregnancy outcomes. J Clin Endocrinol Metab 96(6): E920-E924.

10. Ghafoor F, Mansoor M, Malik T, Khan AU, Edwards R, et al. (2006) Role of thyroid peroxidase antibodies in the outcome of pregnancy. J Coll Physicians Surg Pak 16(7): 468-471.

11. Stewart AAM, Krasnow JS, Brekosky J, DeLoia JA (1998) Endometrial leukocytes are altered numerically and functionally in women with implantation defects. Am J Reprod Immunol 39(1): 1-11.

12. Kwak KJY, Chung BHS, Ng SC, Ntrivalas EI, Mangubat CP, et al. (2003) Increased thelper 1 cytokine responses by circulating $t$ cells are present in women with recurrent pregnancy losses and in infertile women with multiple implantation failures after IVF. Hum Reprod 18(4): 767-773.

13. Raghupathy R, Makhseed M, Azizieh F, Omu A, Gupta M, et al. (2000) Cytokine production by maternal lymphocytes during normal human pregnancy and in unexplained recurrent spontaneous abortion. Hum Reprod 15(3): 713-718.
Creative Commons Attribution 4.0 International License

For possible submissions Click Here

\section{Submit Article}

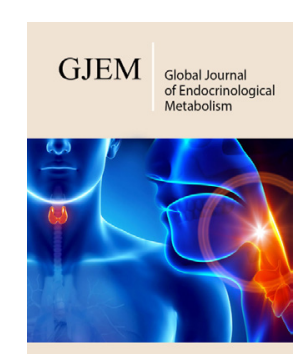

Global Journal of Endocrinological Metabolism

\section{Benefits of Publishing with us}

- High-level peer review and editorial services

- Freely accessible online immediately upon publication

- Authors retain the copyright to their work

- Licensing it under a Creative Commons license

- Visibility through different online platforms 